\title{
Reconsolidation: the samsara of memory consolidation
}

\author{
Cristina M. Alberini
}

Received: 18 December 2006 / Accepted: 2 January 2007 /Published online: 23 February 2007

(C) Springer + Science Business Media, LLC 2007

\begin{abstract}
Memory formation is a complex and very dynamic process. After a learning event, the acquired information undergoes a number of changes that eventually result in memory storage. Stored memories are very malleable. Recent rediscoveries show that after reactivation, for example by retrieval, an established memory can become transiently sensitive to disruption and needs to undergo a process of restabilization, known as reconsolidation, to be maintained. The findings that stabilized memories can become labile have challenged the classical view of how memories are consolidated over time and stored. On the other hand, the reconsolidation process is not fully understood, and theories about the nature and function of memory reconsolidation remain controversial. In this paper, I will present my view on some of the controversial issues of memory reconsolidation and propose a hypothetical model for how this process contributes to memory stabilization. The debated issues that will be discussed are: (1) The term reconsolidation; (2) Temporal constraints of memory reconsolidation; (3) Classical theory of memory consolidation versus theory of memory reconsolidation; (4) Procedural constraints: what is it that needs to be reactivated to produce memory fragility? (5) Functions of memory reconsolidation; (6) Disrupting reconsolidation: an impairment of memory stabilization or retrieval?
\end{abstract}

C. M. Alberini $(\bowtie)$

Department of Neuroscience, Mount Sinai School of Medicine, Box 1065, New York, New York 10029, USA

e-mail: Cristina.Alberini@mssm.edu

C. M. Alberini

Department of Psychiatry, Mount Sinai School of Medicine,

Box 1065, New York, New York 10029, USA
Keywords memory · consolidation · reconsolidation · amnesia $\cdot$ protein synthesis inhibitors

The process of transforming newly learned information into long-lasting memory has been the object of interest of many scientists throughout the last century [1-4]. Studies of verbal learning and trauma-induced retrograde amnesia in humans that began more than 100 years ago lead to the idea that memories become long-lasting through a process of "consolidation" [5]. Over the last century, this process has been extensively investigated behaviorally, pharmacologically, and molecularly in many species, including humans. The conclusion drawn from these studies indicated that consolidation is an evolutionarily conserved process of memory formation that requires an initial phase of RNA and protein synthesis $[1-4,6-8]$.

The classical view proposes that memory consolidation is a unitary process through which a newly formed memory, which is initially sensitive to disruption, becomes stable over time; once stabilized, the memory remains insensitive to disruption. Disrupting events include brain trauma, seizure, electroconvulsive shock (ECS), brain cooling, new learning, and the administration of drugs such as inhibitors of protein and RNA synthesis.

In conflict with this view, recent results, extending earlier observations, show that after reaching a "stable" state, memory can become transiently labile again if reactivated, for example, by recall [9-12]. Events able to disrupt a reactivated memory are the same as those found to be effective in disrupting consolidation including treatments that inhibit molecular mechanisms or protein synthesis in general. The process by which a labile memory again becomes stable and therefore insensitive to disruption has been termed reconsolidation, reminiscent of the labile 
phase of the posttraining consolidation process. Thus, it has been proposed that, in contrast to what was hypothesized by the classical theory of consolidation, when a memory is recalled or reactivated it undergoes a reconsolidation process that again stabilizes the labile memory $[9,13,14]$.

Before discussing specific controversial issues between the two views, I would like to point out that, in my opinion, several disputes originate from confusion surrounding the use of the term consolidation. With the explosion of molecular studies, the term consolidation has often been used to refer to the early requisite phases of transcription and translation, implying that, once it has past, the protein synthesis-dependent phase, a memory is "consolidated." However, earlier findings indicated that other manipulations that affect the physiological activity of brain areas or system networks, such as hippocampal inactivation, lesion, or ablation, can affect the stability of memory for periods of time that long exceed the initial phase of gene expression, lasting for weeks in rodents and years in humans [15-20]. Hence, there are questions that need to be addressed in relation to the temporal delimitation of memory consolidation. Are we looking at distinct consolidation processes or phases when we use different interference approaches? When does the posttraining consolidation process end? Can we identify experimental parameters that can define and temporally delimit the process of memory consolidation? It seems reasonable to believe that, indeed, different interfering manipulations target different phases or perhaps different stages of memory consolidation. In fact, the same memory would be considered consolidated in studies that use protein synthesis inhibitors, but still unconsolidated in investigations that assess, for example, its hippocampal dependence.

This discrepancy could be explained, for example, by the fact that a transient blockade of protein synthesis may not affect phases of memory stabilization utilizing the activity or functions of a neuronal network supported by an existing large pool of proteins or proteins that have a long half-life. A similar interpretation has recently been offered by Paul Gold [21] in his insightful review, which summarizes and discusses the field of retrograde amnesia. He states that "retrograde amnesia gradients do not reveal time courses of memory processes." In summary, I believe that ambiguities about how we in the field define the posttraining consolidation process reflect, in large part, the different results and conclusions emerging from studies that used different amnestic treatments.

Reconsolidation Despite the semantic debate about consolidation and reconsolidation, several studies of the last few years have demonstrated that reconsolidation only partially recapitulates the anatomical, pharmacological, and molecular substrates of consolidation [11, 12, 22]. One study also reported the existence of molecular signatures that doubly dissociate the two processes [23]. Extensive reports and discussions regarding this topic have been provided in previous reviews [11, 12, 24, 25]. The general conclusions, with which I agree, seem to argue that reconsolidation is not a re-consolidation, and, it is now generally accepted that the term reconsolidation is used not to mean faithful repetition of the initial posttraining consolidation, but rather the functional outcome of the process, which is to make memory stable again.

Temporal constraints The hypothesis that whenever a memory is retrieved or reactivated it again becomes labile and "disruptable" $[9,10,24]$ has been challenged. Studies from my laboratory, as well as those of several others, have pointed out that the passage of time is a limiting factor for the postretrieval vulnerability of memory. Using the fearconditioning-based task inhibitory avoidance, we have found that systemic inhibition of protein synthesis resulted in decrementally graded amnesia of 2-day- and 1-week-old memories while leaving intact 2-week- and 4-week-old memories [26]. We recently confirmed these results using bilateral amygdala injections of either the protein synthesis inhibitor anysomycin or antisense DNA sequences specific for the transcription factor CCAAT enhancer binding protein $\beta(\mathrm{C} / \mathrm{EBP} \beta)$ (27; Milekic et al., unpublished). We conclude that upon reactivation, an older memory does not become fragile to the same degree as a young one does, and that, over time, memory becomes increasingly stable and insensitive to the postreactivation interference. Based on this, I would like to argue that the reconsolidation phenomenon reflects a fragile state of a memory that has not yet been fully consolidated, although it has passed the initial protein synthesis-dependent phase. Thus, as detailed below, I propose that reconsolidation is a phase of the overall consolidation process [12], and I will refer to the gradient of postretrieval fragility as the consolidation gradient. Several other studies reported outcomes that are in agreement with ours. Litvin and Anokin [28] found that in chicks intracerebral administration of the protein synthesis inhibitor cycloheximide $5 \mathrm{~min}$ before a passive avoidance reminder procedure, which was performed 2 , 24 , or $48 \mathrm{~h}$ after training, resulted in temporary amnesia that gradually decreased in duration as the interval between training and reminding increased. The authors concluded that: "quenching of the ability of protein synthesis inhibition during the reminder to disrupt memory demonstrates the existence of a gradual process resulting in consolidation of memory between 2 and $48 \mathrm{~h}$ of learning". Eisenberg and Dudai [29] also reported that with respect to Medaka fish fear memories, administration of a $\mathrm{Na}+$ channel blocker upon reactivation disrupts a 4-day-old memory, but has no effect on a 15-day-old one and has an intermediate effect on a 9-day-old memory. Additional corroboration of the same 
phenomenon was provided by Suzuki et al. [30] who, using systemic anisomycin injections in mice at time points covering an 8-week temporal window after training, elegantly showed that contextual fear conditioning displays a gradient of postreactivation fragility. They found that this fragility is a function not only of the age, but also of the strength of the memory, as well as on the extension of the reactivation, so that weaker memories are more easily reconsolidated than are stronger ones. Moreover, Boccia et al. [31] showed that in mice trained in inhibitory avoidance the intracerebral injection (i.c.v.) injection of an inhibitor of high-affinity choline uptake after memory retrieval led to amnesia at later tests if the memory was reactivated either at 2 , 7, or 14 days after training; however, a 30-day-old memory that underwent the same treatment remained intact. Frankland et al. [32] reported similar effects using brainregion-restricted inhibition of protein synthesis. They examined the effect of postretrieval anisomycin injections into either the dorsal hippocampus or anterior cingulate cortex of 1-day-old (recent) and 36-day-old (remote) contextual fear memory in mice, finding that, in the dorsal hippocampus, anisomycin disrupted subsequent expression of recent but not remote memory. Similar infusions into the anterior cingulate cortex had no effect on either recent or remote contextual fear memories, whereas systemically applied anisomycin blocked remote memory expression only when long reexposure durations were used to retrieve the memory. The dissociation between the effects of systemically and centrally administered anisomycin on remote memory led the authors to suggest that memory stability is due, in part, to the distributed nature of remote contextual fear memory traces.

Different interpretations and conclusions have been offered by Nader's group. These authors reported that 2-day- and 2week-old memories of cued-fear conditioning in rats were disrupted by postretrieval bilateral injections of anisomycin into the amygdala [14]. In addition, they found that in contrast to what has been shown by Frankland et al. [32] who used the same contextual fear conditioning task, post-recall anisomycin injection into the dorsal hippocampi of rats disrupts a 45-day-old memory, a time when contextual memory is independent of the hippocampus [33]. Nader's group argues that retrieval-induced memory lability applies to remote memories and that "contextual memories associated with shock always seem to be able to return to a labile state after reactivation" $[24,33]$. In my view, this conclusion may be premature. In agreement with the aforementioned literature, and consistent with the conclusions of Suzuki et al. [30], a reasonable explanation for Nader's results is that the temporal profile of the reconsolidation gradient is a function of several parameters, including strength of the original memory, strength of the reactivation protocol, and the passage of time. I would add to this list one more parameter, the nature of the task. All these aspects likely contribute to the degree and duration of the postreactivation gradient of fragility. Hence, under the experimental conditions used by Nader's group (e.g., the reactivation time points chosen), the memory may still lie within the labile period. Moreover, it will not be inconsistent with the consolidation gradient results that, under certain circumstances, the stabilization process that occurs over time may never reach a plateau and some memories may remain sensitive to postretrieval interference for a very long time, even indefinitely. Interestingly, for example, memories that require multiple training trials to consolidate appear to show a long-lasting temporal window of postreactivation fragility. Diergaarde et al. [34] reported that a 21-day-old appetitive instrumental response (sucrose self-administration) is disrupted by systemic injection of the $\beta$-adrenergic antagonist propranolol. Moreover, Lee et al. [35] showed that a 27-days-old cocaine-induced conditioned place preference is disrupted by postreactivation amygdala injections of zif268 antisense. In my opinion, a possible explanation for these results is that the consolidation gradient of these multiple-training trial-induced memories is a function of the number, frequency, and intensity of training trials, and that the protocol used in the studies described above produced memories that were not yet not fully consolidated at the chosen testing times. This hypothesis is testable and further studies should be able to address this point.

An important point that I would like to stress for the purpose of clarity is that the existence of a gradient does not necessarily mean that a remote memory, insensitive to protein synthesis inhibition after retrieval, does not undergo "reactivation-induced" changes. Rather, postreactivation changes occur without manifested fragility of the consolidated information. This view would agree with the idea that memory stability correlates with the distributed nature of the memory trace [36].

Hence, based on the consolidation gradient results, how do we explain memory reconsolidation?

Classical theory of memory consolidation versus theory of memory reconsolidation As mentioned earlier, one point overlooked by the classical theory of memory consolidation is that a memory could undergo rounds of "consolidation" after reminders of the learned event. The classical view regarded memory consolidation as a unitary process. On the other hand, the reconsolidation hypothesis suggested that whenever memory undergoes reactivation it becomes labile $[9,24]$. However, this hypothesis, as described above, has also failed.

Although it is important to gain further understanding of the reconsolidation process before affirming what it signifies, for the sake of debate, I would like to propose a hypothetical model that explains the function of memory reconsolidation. It is known that facts and events become 
long-lasting memories if they are salient. Experimentally, it has been shown that modulatory inputs can make memory traces stronger as well as weaker [37]. These inputs appear to be intimately associated with systems that convey the importance of the experienced event. Interestingly, pharmacological treatment can often be substituted for practice to strengthen the memory trace, suggesting that a drug or practice activates a common mechanism [38]. There is obviously a gradient of salience among different experiences and, at one end, there are, for example, traumatic and aversive events. These types of events are generally remembered for a very long time, often a lifetime. Do we need to reexperience September 11 to remember it? Obviously not, and such a retraining event would represent an additional life-threat that the principle of conservation of our biological nature has evolved to avoid. How, then, do we memorize a one-trial learning experience for a long time? I propose that this occurs through reconsolidation processes induced by recall, which, by safely reactivating the trace of the aversive training event, increasingly stabilizes memory, similar to what multiple training trials are required to do to stabilize the memory of emotionally neutral events. I propose that the degree of salience (and therefore the evoked arousal and modulation) of learned events correlates with the frequency of memory reactivation (implicit and explicit) and therefore with the profile of the consolidation gradients and the strength and duration of the memories. According to this view, whereas other types of memory (e.g., procedural) consolidate through many repetitions of trials, a one-time aversive (or emotionally charged) learning would consolidate into a long-lasting memory by repeatedly recalling and reactivating the original experience (implicit and explicit recollections) and, consequently, all the sequelae of underlying molecular reconsolidation changes, until the memory becomes stable. Thus, memory reactivation produces a process of reconsolidation to stabilize or consolidate the memory. In other words, reconsolidation is likely a phase of the overall consolidation process [12].

Accordingly, reactivation might also be used to mediate the maintenance of the memory over time; that is, to prevent forgetting. In these instances, the memory, or the parts of the memory that become reactivated upon the urge of present experiences, by undergoing reconsolidation, would prolong the storage of the information that is reactivated.

Procedural constraints: what is it that needs to be reactivated to produce memory fragility? Virtually nothing is known about this important issue. In my view, important and testable questions exist that may help us understand why there is a gradient of increasing resistance to postreactivation memory disruption. First, is it the ratio between the extent of the reactivated memory trace versus the extent of the consolidated trace that makes a memory sensitive to disruption? Or is it the nature of the reactivated representations that have different valences? Finally, do the intrinsic characteristics of the trace change over time?

Although the answers to these questions are not yet available, several studies have provided interesting relevant information. In line with the results of Suzuki et al. [30] and Frankland et al. [32], a "stronger" reactivation makes a memory labile, whereas a weaker reactivation of the same memory is ineffective, suggesting that memory stability may be caused, in part, by the distributed nature of the memory trace and the extent of the reactivated trace [32, 36]. In addition, training trials are effective as reactivation procedures [39-45] in inducing reconsolidation, whereas recall procedures represented by the conditioned stimulus (CS) alone are sometimes ineffective [42, 46, 47]. Finally, only directly reactivated memories, not indirectly reactivated ones, undergo reconsolidation in the amygdala [48].

What is the function of memory reconsolidation? Why do memories become labile after reactivation? Two nonmutually exclusive hypotheses have been proposed to address this question: (1) retrieval strengthens memory retention [13], and (2) retrieval triggers a reconsolidation process that allows the integration of new information into the background of the past (memory updating). In other words, reconsolidation allows us "to associate new learning with already established and reactivated memories" [9, 11, 49].

As described above, the first is the hypothesis that I strongly endorse as a functional explanation for the role of reconsolidation. Although the literature is rich with suggestions supporting the idea that memory reactivation increases memory strength and prevents forgetting, to my knowledge, no systematic study addressing this issue has yet been provided. However, supporting evidence include, for example, a recent finding by Parvez et al. [50] showing that memory reactivation through the reexperience of a single contingent-reinforcing stimulus given in the same context as previous intermediate-term memory training boosts a residual memory trace into long-term memory. In addition, electrical stimulation of the mesencephalic reticular formation (MRF) improves the retention of memories, including fear conditioning and linear maze, when the stimulus is applied after reactivation [13, 51]. Finally, clear evidence has recently shown that during the reconsolidation phase memory retention can be increased by pharmacological modulation $[52,53]$, suggesting that after reactivation memory can be strengthened.

Regarding the second hypothesis, my laboratory has attempted to address the question of whether the reconsolidation process is used to mediate the formation of associations between new and reactivated information by 
using second-order conditioning [27]. This procedure occurs in a two-step paradigm. First, a conditioned stimulus (CS1) is paired with an unconditioned stimulus (US). Then the established properties of CS1 are paired with a new stimulus, CS2, producing a CS1-CS2 association [54].

Thus, using the inhibitory avoidance (IA) task, we first established the formation of an IA fear memory for a context A (CS1) using a footshock (US). We subsequently presented a neutral cue originally present in context A (CS1) in a new context, B (CS2), and showed that animals develop IA in context $\mathrm{B}$, although this context has never been paired with a shock. Using systemic inhibition of protein synthesis, we observed that both the new association (CS2-CS1) and the recalled memory (CS2-US) are labile after reactivation of the original memory, which occurs while the new association is formed. However, using region-restricted molecular disruption, we found that the reconsolidation of the original memory takes place independently from the formation of the new association. In fact, the two processes are mechanistically distinct because they are doubly dissociable: the inhibition of a molecular mechanism required for memory reconsolidation, namely, the expression of $\mathrm{C} / \mathrm{EBP} \beta$ in the amygdala, selectively disrupts the reactivated memory while leaving the new association intact. Conversely, the formation of the new association is mediated by molecular mechanisms similar to those underlying the initial consolidation of a new memory. Indeed, hippocampal inhibition of protein synthesis or $\mathrm{C} /$ EBP $\beta$ expression, which selectively disrupts the consolidation of new IA memories, impairs the retention of the new association, but leaves the old memory intact. Thus, although the process of retrieving a memory is necessary for linking new information with reactivated memories, the retrieval-induced reconsolidation process is not engaged in linking the new information with the reactivated memory.

A study by Rodriguez-Ortiz et al. [45] investigated memory updating from a different angle and using a different task, that is, attenuation of neophobia (AN) in rats. AN is represented by a gradual increase in tastant intake after repeated presentations of the same tastant. Repeated learning presentations of the tastant were used to test the relationship between the new learning event and the consolidated memory established by previous trials as well as the fragility of both new and previously established memories. The authors referred to each additional learning as memory updating. Using multiple training trials, each separated by $24 \mathrm{~h}$, they found that infusion of anisomycin into the insular cortex after the first, second, or third trial significantly disrupted memory retention; however, the disruption observed after the third trial was only partial. On the other hand, anisomycin injected after six trials had no significant effect. Thus, they concluded that, whereas additional learning is acquired, part of the older, consoli- dated memory in the insular cortex becomes independent of protein synthesis. Furthermore, rats that after seven trials of attenuation of neophobia underwent training in conditioned taste aversion (CTA) for the same taste in the presence of anisomycin developed amnesia for CTA the following day. The authors concluded that "protein synthesis is required to update previously consolidated memory trace regardless of the valence of the tastant." This study, in agreement with our results, indicates that the formation of the new association linked to a previously established memory requires protein synthesis. However, it did not determine whether it is the protein synthesis required for the reconsolidation of the old memory that is recruited to mediate the incorporation of new information. Thus, in line with what is suggested by our results, it is possible that this type of memory updating also recruits a consolidation-like process and not the reconsolidation of the original memory. Indeed, consistent with our findings, the study by Rodriguez-Ortiz et al. [45] shows that the old and new memories are dissociable processes because, whereas the old memory can become insensitive to disruption (consolidated), the incorporation of the new information (or updating, as referred to by the author) remains sensitive to disruption.

The distinction between reconsolidation of an original memory and making a new association between new and reactivated information is an important one. Our studies indicate that they are distinct because they can be experimentally doubly dissociated and that linking new and reactivated information is not memory reconsolidation, but rather the formation of a new memory. This point should be kept in mind when discussing results such as the one above by Rodriguez-Ortiz et al. [45] and those of Lee et al. [55] who examined the effect of memory reactivation on the formation of new associations and referred to this as reconsolidation. Lee et al. [55] showed that the infusion of zif268 antisense oligodeoxynucleotides into the basolateral amygdala before the reactivation of a well-learned memory for a CS-cocaine association abolishes the acquisition of a new instrumental cocaine-seeking response.

In conclusion, I propose that memory updating is a process similar to the consolidation of a new memory and distinct from the reconsolidation of established memories.

Disrupting reconsolidation: an impairment of memory stabilization or retrieval? One of the oldest and still unresolved problems of postconsolidation and postreconsolidation amnesia is whether they represent retrieval or storage deficits $[24,49,56-60]$. Is memory disruption after retrieval an elimination of the physical trace of the memory or is it a reduction of its expression? Two criteria are often used to dissect these questions: the exposure to reminder stimuli and testing for the persistence of amnesia. In both cases, the recovery of memory argues in favor of retrieval 
deficits. Thus far, the published results, and therefore the conclusions, have been mixed. In several cases it has been reported that the memory deficits observed after the administration of interfering agents or events after retrieval were transient and that memory resumed after some time (e.g., [57, 61-63]). Moreover, in some cases the experience of a reminder event readily recovered the memory (e.g., [64]). In contrast, a number of other studies have shown that the amnesia produced by postretrieval treatments is persistent (e. g., [30, 33, 42, 43, 46, 65-68]). In many cases, the experience of a reminder has failed to restore memory retention (e.g. [43, 46, 67, 68]), suggesting that, at least in some circumstances, memory disruption may reflect a weakening of the stored trace.

Several authors seem to agree that the amnesia caused by postreactivation interference is a retrieval deficit $[57,58,69]$. However, I would argue that, in favor of the consolidation deficit view, it is possible that, at least in some cases, the evidence for a retrieval deficit emerges when, because of the protocols used to reactivate the memory, (i.e., duration of CS exposure), an accelerated extinction rather than a block in reconsolidation has been evoked [70-72].

Although, we never targeted this issue in our studies, for the sake of discussion, I direct attention to two of our results, which seem to argue for a loss of consolidated or consolidating information rather than a retrieval deficit. The first addresses an explanation for the observed age-related gradient of amnesia. We found that a 2-day-old IA reactivated memory is disrupted by protein synthesis inhibition, whereas one that is 2 weeks old is not. How can we explain these results as retrieval impairment? Is the retrieval process different for memories of different ages? Or, on the contrary, is it the memory trace that changes over time and, while unretrievable at 2 days, becomes retrievable at 2 weeks? If the latter is true, what is it about the intrinsic nature of the memory that changes over time and becomes unretrievable after interfering treatments? And, does this not remind us of a time-dependent consolidation process?

The second result originated from the second-order IA conditioning studies [28] described earlier. The rats that underwent training for context A (CS1-US) and then memory reactivation in context $\mathrm{B}$ and, in this context, formed a new association with the previous memory (CS1CS2), showed amnesia for the context B after hippocampal disruption of either protein synthesis or $\mathrm{C} / \mathrm{EBP} \beta$. However, at the same time, the old memory for context A was unaffected by the same treatment and was, in fact, normally retrieved. Conversely, $\mathrm{C} / \mathrm{EBP} \beta$ disruption in the amygdala resulted in amnesia of the original memory for context A but left the retrieval of memory for context $\mathrm{B}$ intact. Because the retention of only one memory (IA for one context) and not the other similar one was reciprocally affected, these findings suggest that the retrieval apparatus is intact, supporting the idea that the selective amnesia of one memory might be caused by a storage deficit.

In conclusion, although several authors support the idea of retrieval deficit to explain amnesia caused by reconsolidation interference, several results argue against this, and further investigation is required to settle this issue.

Acknowledgments Many thanks to all the members of my lab for their invaluable contribution to the work discussed and for their helpful feedbacks on the manuscript, and to Dr. Reginald Miller and the CCMS facility of Mount Sinai for technical support. The work included in this review was supported by the National Institute of Mental Health (R01 MH65635), National Institute of Drugs of Abuse (R21 CEBRA DA017672), and the Hirschl Foundation to CMA.

\section{References}

1. Squire LR, Alvarez P (1995) Retrograde amnesia and memory consolidation: a neurobiological perspective. Curr Opin Neurobiol 5:169-177

2. Bailey CH, Bartsch D, Kandel ER (1996) Toward a molecular definition of long-term memory storage. Proc Natl Acad Sci USA 93:13445-134452

3. McGaugh JL (2000) Memory - a century of consolidation. Science 287:248-251

4. Dudai Y (2002) Molecular bases of long-term memories: a question of persistence. Curr Opin Neurobiol 12:211-216

5. Muller GE, Pilzecker A (1900) Experimentelle Beitrage zur Lehre vom Gedachtniss Z. Psych Eranzungaband 1:1-288

6. McGaugh JL (1966) Time-dependent processes in memory storage. Science 153:1351-1358

7. Davis HP, Squire LR (1984) Protein synthesis and memory: a review. Psychol Bull 96:518-559

8. Kandel ER (2001) The molecular biology of memory storage: a dialog between genes and synapses. Biosci Rep 21:565-611

9. Sara SJ (2000b) Retrieval and reconsolidation: toward a neurobiology of remembering. Learn Mem 7:73-84

10. Nader K, Schafe GE, LeDoux JE (2000a) The labile nature of consolidation theory. Nat Rev Neurosci 1:216-219

11. Dudai Y (2004) The neurobiology of consolidations, or, how stable is the engram? Annu Rev Psychol 55:51-86

12. Alberini CM ( 2005) Mechanisms of memory stabilization: are consolidation and reconsolidation similar or distinct processes? Trends Neurosci 28:51-56

13. Sara SJ (2000a) Strengthening the shaky trace through retrieval. Nat Rev Neurosci 1:212-213

14. Nader K, Schafe GE, Le Doux JE (2000b) Fear memories require protein synthesis in the amygdala for reconsolidation after retrieval. Nature 406:722-726

15. Kim JJ, Clark RE, Thompson RF (1995) Hippocampectomy impairs the memory of recently, but not remotely, acquired trace eyeblink conditioned responses. Behav Neurosci 109:195-203

16. Anagnostaras SG, Maren S, Fanselow MS (1999) Temporally graded retrograde amnesia of contextual fear after hippocampal damage in rats: within-subjects examination. J Neurosci 19:1106-1114

17. Mumby DG, Astur RS, Weisend MP et al (1999) Retrograde amnesia and selective damage to the hippocampal formation: 
memory for places and object discriminations. Behav Brain Res 106:97-107

18. Squire LR, Clark RE, Knowlton BJ (2001) Retrograde amnesia. Hippocampus 11:50-55

19. Squire LR, Clark RE, Bayley PJ (2004) Medial temporal lobe function and memory. In: Gazziniga $M$ (ed) The cognitive neurosciences, 3rd edn. MIT Press, Cambridge, MA, pp. 691-708

20. Winocur G, McDonald RM, Moscovitch M (2001) Anterograde and retrograde amnesia in rats with large hippocampal lesions. Hippocampus 11:18-26

21. Gold PE (2006) The many faces of amnesia. Learn Mem 13:506-514

22. von Hertzen LS, Giese KP (2005) Memory reconsolidation engages only a subset of immediate-early genes induced during consolidation. J Neurosci 25:1935-1942

23. Lee JL, Everitt BJ, Thomas KL (2004) Independent cellular processes for hippocampal memory consolidation and reconsolidation. Science 304:839-843

24. Nader K (2003) Memory traces unbound. Trends Neurosci 26:65-72

25. Nader K, Hardt O, Wang SH (2005) Response to Alberini: right answer, wrong question. Trends Neurosci 28:346-347

26. Milekic MH, Alberini CM (2002) Temporally graded requirement for protein synthesis following memory reactivation. Neuron 36:521-525

27. Tronel S, Milekic MH, Alberini CM (2005) Linking new information to a reactivated memory requires consolidation and not reconsolidation mechanisms. PLoS Biol e293

28. Litvin OO, Anokhin KV (2000) Mechanisms of memory reorganization during retrieval of acquired behavioral experience in chicks: the effects of protein synthesis inhibition in the brain. Neurosci Behav Physiol 30:671-678

29. Eisenberg M, Dudai Y (2004) Reconsolidation of fresh, remote, and extinguished fear memory in Medaka: old fears don't die. Eur J Neurosci 20:3397-3403

30. Suzuki A, Josselyn SA, Frankland PW et al (2004) Memory reconsolidation and extinction have distinct temporal and biochemical signatures. J Neurosci 24:4787-4795

31. Boccia MM, Blake MG, Acosta GB et al (2006) Post-retrieval effects of icv infusions of hemicholinium in mice are dependent on the age of the original memory. Learn Mem 13:376-381

32. Frankland PW, Ding HK, Takahashi E et al (2006) Stability of recent and remote contextual fear memory. Learn Mem 13:451-4577

33. Debiec J, LeDoux JE, Nader K (2002) Cellular and systems reconsolidation in the hippocampus. Neuron 36:527-538

34. Diergaarde L, Schoffelmeer AN, De Vries TJ (2006) Betaadrenoceptor mediated inhibition of long-term reward-related memory reconsolidation. Behav Brain Res 170:333-336

35. Lee JL, Milton AL, Everitt BJ (2006) Cue-induced cocaine seeking and relapse are reduced by disruption of drug memory reconsolidation. J Neurosci 26:5881-5887

36. Nadel L, Moscovitch M (1997) Memory consolidation, retrograde amnesia and the hippocampal complex. Curr Opin Neurobiol 7:217-227

37. Cahill L, McGaugh JL (1996) Modulation of memory storage. Curr Opin Neurobiol 6:237-242

38. Martinez JL Jr, Weinberger SB (1987-1988) Memory traces: how to increase and decrease their strength. Int J Neurol 21-22:33-50

39. Mactutus CF, Riccio DC, Ferek JM (1979) Retrograde amnesia for old reactivated memory: some anomalous characteristics. Science 204:1319-1320

40. Richardson R, Riccio DC, Mowrey H (1982) Retrograde amnesia for previously acquired Pavlovian conditioning: UCS exposure as a reactivation treatment. Physiol Psychol 10:384-390

41. Kelly A, Laroche S, Davis S (2003) Activation of mitogenactivated protein kinase/extracellular signal-regulated kinase in hippocampal circuitry is required for consolidation and reconsolidation of recognition memory. J Neurosci 23:5354-5360
42. Bozon B, Davis S, Laroche S (2003) A requirement for the immediate early gene zif268 in reconsolidation of recognition memory after retrieval. Neuron 40:695-701

43. Duvarci S, Nader K (2004) Characterization of fear memory reconsolidation. J Neurosci 24:9269-9275

44. Inda MC, Delgado-Garcia JM, Carrion AM (2005) Acquisition, consolidation, reconsolidation, and extinction of eyelid conditioning responses require de novo protein synthesis. J Neurosci 25:2070-2080

45. Rodriguez-Ortiz CJ, De la Cruz V, Gutierrez R et al (2005) Protein synthesis underlies post-retrieval memory consolidation to a restricted degree only when updated information is obtained. Learn Mem 12:533-537

46. Milekic MH, Brown SD, Castellini C et al (2006) Persistent disruption of an established morphine conditioned place preference. J Neurosci 26:3010-3020

47. Valjent E, Corbille AG, Bertran-Gonzalez J et al (2006) Inhibition of ERK pathway or protein synthesis during reexposure to drugs of abuse erases previously learned place preference. Proc Natl Acad Sci USA 103:2932-2937

48. Debiec J, Doyere V, Nader K et al (2006) Directly reactivated, but not indirectly reactivated, memories undergo reconsolidation in the amygdala. Proc Natl Acad Sci USA 103:3428-3433

49. Lewis DJ (1979) Psychobiology of active and inactive memory. Psychol Bull 86:1054-1083

50. Parvez K, Moisseev V, Lukowiak K (2006) A context-specific single contingent-reinforcing stimulus boosts intermediate-term memory into long-term memory. Eur J Neurosci 24:606-616

51. DeVietti TL, Holliday JH, Larson RC (1973) Comparison of amnesias induced by electroconvulsive shock administered after training-trial footshock or noncontingent footshock in rats. J Comp Physiol Psychol 84:579-585

52. Frenkel L, Maldonado H, Delorenzi A (2005) Memory strengthening by a real-life episode during reconsolidation: an outcome of water deprivation via brain angiotensin II. Eur $\mathrm{J}$ Neurosci 22:1757-1766

53. Tronson NC, Wiseman SL, Olausson P et al (2006) Bidirectional behavioral plasticity of memory reconsolidation depends on amygdalar protein kinase A. Nat Neurosci 9:167-169

54. Rescorla, RA (1980) Pavlovian second-order conditioning: studies in associative learning. Laurence Erlbaum Associates, Hillsdale (New Jersey), p 120

55. Lee JL, Di Ciano P, Thomas KL et al (2005) Disrupting reconsolidation of drug memories reduces cocaine-seeking behavior. Neuron 47:795-801

56. Riccio DC, Moody EW, Millin PM (2002) Reconsolidation reconsidered. Integr Physiol Behav Sci 37:245-253

57. Lattal KM, Abel T (2004) Behavioral impairments caused by injections of the protein synthesis inhibitor anisomycin after contextual retrieval reverse with time. Proc Natl Acad Sci USA 101:4667-4672

58. Riccio DC, Millin PM, Bogart AR (2006) Reconsolidation: a brief history, a retrieval view, and some recent issues. Learn Mem 13:536-544

59. Nader K, Wang SH (2006) Fading in. Learn Mem 13:530-535

60. Miller CA, Sweatt JD (2006) Amnesia or retrieval deficit? Implications of a molecular approach to the question of reconsolidation. Learn Mem 13:498-505

61. Anokhin KV, Tiunova AA, Rose SP (2002) Reminder effectsreconsolidation or retrieval deficit? Pharmacological dissection with protein synthesis inhibitors following reminder for a passiveavoidance task in young chicks. Eur J Neurosci 15:1759-1765

62. Salinska E, Bourne RC, Rose SP (2004) Reminder effects: the molecular cascade following a reminder in young chicks does not recapitulate that following training on a passive avoidance task. Eur J Neurosci 19:3042-3047 
63. Power AE, Berlau DJ, McGaugh JL, Steward O (2006) Anisomycin infused into the hippocampus fails to block "reconsolidation" but impairs extinction: the role of re-exposure duration. Learn Mem 13:27-34

64. Vianna MR, Szapiro G, McGaugh JL et al (2001) Retrieval of memory for fear-motivated training initiates extinction requiring protein synthesis in the rat hippocampus. Proc Natl Acad Sci USA 98:12251-12254

65. Child FM, Epstein HT, Kuzirian AM et al (2003) Memory reconsolidation in hermissenda. Biol Bull 205:218-219

66. Pedreira ME, Maldonado H (2003) Protein synthesis subserves reconsolidation or extinction depending on reminder duration. Neuron 38:863-869

67. Boccia MM, Blake MG, Acosta GB et al (2005) Memory consolidation and reconsolidation of an inhibitory avoidance task in mice: effects of a new different learning task. Neuroscience 135:19-29
68. Tronel S, Alberini CM (2007) Persistent disruption of a traumatic memory by post-retrieval inactivation of glucocorticoid receptors in the amygdala. Biol Psych Jan. 2; [Epub ahead of print]

69. de Hoz L, Martin SJ, Morris RG (2004) Forgetting, reminding, and remembering: the retrieval of lost spatial memory. PLoS Biol 2:E225

70. Koh MT, Bernstein IL (2003) Inhibition of protein kinase A activity during conditioned taste aversion retrieval: interference with extinction or reconsolidation of a memory? NeuroReport 14:405-407

71. Fischer A, Sananbenesi F, Schrick C et al (2004) Distinct roles of hippocampal de novo protein synthesis and actin rearrangement in extinction of contextual fear. J Neurosci 24:1962-1966

72. Cai WH, Blundell J, Han J et al (2006) Postreactivation glucocorticoids impair recall of established fear memory. J Neurosci 26:9560-9566 